\title{
Epithelial-mesenchymal transition in glioblastoma progression (Review)
}

\author{
YASUO IWADATE \\ Department of Neurological Surgery, Graduate School of Medicine, Chiba University, Chiba 260-2870, Japan
}

Received March 6, 2015; Accepted December 10, 2015

DOI: $10.3892 / \mathrm{ol} .2016 .4113$

\begin{abstract}
Epithelial-mesenchymal transition (EMT) is a reversible biological process that occurs in epithelial cells. EMT ultimately leads to the acquisition of a mesenchymal phenotype, characterized by increased cell motility and resistance to genotoxic agents. These processes mostly overlap with the acquirement of stem cell properties in differentiated tumor cells. With regard to gliomas, the clinical picture is heterogeneous, even within the same grades and histological categories of the disease. Furthermore, the areas of invasion and responses to radiochemotherapy are markedly different among cases, and occasionally even in the same patient. Such phenotypic diversity in glioma tissues may be caused by various microenvironmental factors, as well as intrinsic genetic alterations. The current review focuses on the EMT-inducing factors that are present in gliomas; these typically vary from those observed in epithelial cancers, as no basement membrane is present. Furthermore, the most important cell-cell contact factor, E-cadherin, is rarely expressed in gliomas. The microenvironment that induces EMT in gliomas is characterized by hypoxia and the enrichment of myeloid cells following stimulation by transforming growth factor- $\beta$. Anti-vascular endothelial growth factor therapy, including the use of bevacizumab, may be a suitable candidate to modulate the glioma microenvironment.
\end{abstract}

\section{Contents}

1. Introduction

2. Classification of EMT

3. EMT-inducing microenvironment

4. EMT-inducing signals in gliomas

5. MicroRNAs (miRs) that regulate EMT in gliomas

Correspondence to: Dr Yasuo Iwadate, Department of Neurological Surgery, Graduate School of Medicine, Chiba University, 1-8-1 Inohana, Chuo-ku, Chiba 260-2870, Japan

E-mail: iwadatey@faculty.chiba-u.jp

Key words: glioma, microRNA, epithelial-mesenchymal transition, stem cell
6. Radiation-induced EMT

7. Bevacizumab-induced EMT

8. Conclusion

\section{Introduction}

Epithelial-mesenchymal transition (EMT) is a biological process in which polarized epithelial cells are induced to undergo numerous biochemical changes; this results in a mesenchymal phenotype, defined by an enhanced migratory capacity and elevated resistance to genotoxic agents $(1,2)$. EMT is indispensable for wound healing, embryonic development and tissue remodeling. As a pathological process, EMT also induces migratory and invasive capabilities in epithelial tumor cells without a loss in viability $(1,2)$. The process of EMT includes the detachment of tumor cells from the basement membrane. Although the central nervous system (CNS) lacks this critical tissue component, key invasive mechanisms overlap between cancers of the CNS and other cancer types (3). The factors that induce EMT in other cancers may also activate mesenchymal features in gliomas (Fig. 1). Furthermore, EMT is an important inducer of the cancer stem cell phenotype (4). The mesenchymal subtype of glioblastoma (GBM) typically expresses neural stem cell markers and is associated with an aggressive phenotype (5-7). Glioma cells that express stem cell markers are highly invasive and resistant to chemotherapy and radiotherapy in vitro (8-10) and in the clinical setting (11).

Gliomas are classified according to their histopathological features; these features allow clinicians to distinguish between two cellular lineages (astrocytic and oligodendrocytic) and four grades of malignancy (grades I to IV) (12). The most malignant form of grade IV is GBM, which originates from progenitor or stem cells in the astrocytic lineage. Recent genotyping and expression profiling analyses have demonstrated that GBMs may be categorized into four subclasses dependent on their neural differentiation $(5,6)$. The proneural subtype is associated with a positive prognosis, whilst the mesenchymal subtype is characterized by higher percentages of cycling cells and neoangiogenesis, with a highly invasive nature and poor prognosis $(5,6)$. Furthermore, non-mesenchymal subtypes of tumors typically acquire mesenchymal features at recurrence (6). A shift towards the mesenchymal subtype appears to be a common pattern in disease progression, similar to cancer 


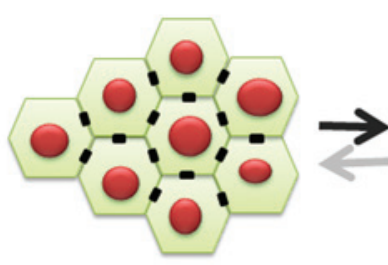

Glioma cells fixed with some adhesion molecules

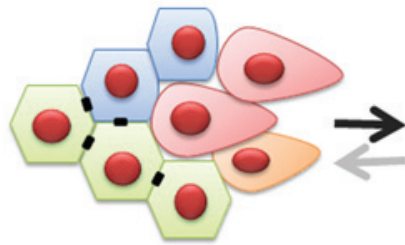

Remodeling of cytoskeleton Loss of adhesion molecules

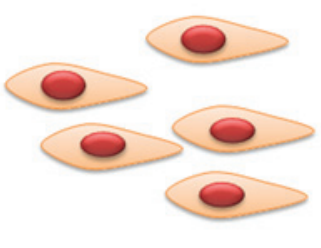

Highly invasive phenotype

Figure 1. Scheme for the epithelial-mesenchymal transition in glioma cells. Glioma cells lose adhesion molecules and alter their cytoskeleton through a reprogramming process. It is essential that this phenotypic change is reversible, and the reverse process, termed mesenchymal-epithelial transition, is necessary for the formation of distant or disseminated tumor nodules.

cells undergoing EMT in order to acquire a more aggressive nature (13).

Paradoxically, migrating tumor cells are required to lose the mesenchymal phenotype to establish a secondary tumor at distant sites $(1,2)$. This suggests that EMT is a reversible process, and is most likely to be mediated by epigenetic alterations that are induced by microenvironmental stimuli, rather than as a result of genetic alterations $(14,15)$. Differentiated tumor cells change their phenotype through a dynamic reprogramming process that is affected by a repair-associated process or pathological stresses, such as hypoxic insults (16-20). Acquisition of the stem cell phenotype may be closely associated with epigenetic alterations that are induced by EMT. Although EMT may be a common pattern in glioma progression, numerous therapeutic interventions affect the occurrence and magnitude of EMT during the clinical course of GBM (21-23). The present review discusses the participation of EMT in GBM progression, and the resulting acquisition of the stem-cell phenotype.

\section{Classification of EMT}

EMT is classified into three different subtypes $(1,2)$. EMT type 1 is an essential mechanism required for the transitioning of primitive epithelial cells in embryos into motile mesenchymal cells, which are required for the gastrulation and migration of neural crest cells (24). Certain cells generated by EMT become secondary epithelial cells in mesodermal and endodermal organs through a reverse event known as mesenchymal-epithelial transition (MET). Thus, during embryogenesis, type 1 EMT serves a critical role in generating morphologically and functionally distinct cell types, including mesenchymal and secondary epithelial cells, through the process of MET $(1,2)$.

EMT type 2 occurs in adults and is associated with tissue regeneration, wound healing and organ fibrosis, in which fibroblasts are formed in injured tissues. Organ fibrosis is mediated by fibroblasts and inflammatory cells that secrete a number of inflammatory signals alongside the components of a complex extracellular matrix, consisting of elastin, collagens, tenacin and laminins. The transition of epithelial cells into fibroblasts occurring over a few days in culture is one line of evidence for this type of EMT, and an active diversion to MET occurs in the presence of bone morphogenic protein-7 (25). Cancer-associated fibroblasts in primary epithelial tumor nodules have recently been demonstrated to share certain genetic mutations with tumor cells, suggesting that type 2 EMT emerges prior to the full onset of tumorigenesis (26).

EMT type 3 is observed in subsets of cancer cells undergoing a phenotypic conversion to increase migration, invasion and metastasis. Certain studies have noted that transforming growth factor (TGF)- $\beta$ can induce EMT in epithelial cancer cells through Smad or p38 mitogen-activated protein kinase/Ras homolog family member A pathways (27-29). Activation of EMT programs, through tumor microenvironment stimuli, has been proposed as the critical mechanism for the acquisition of highly malignant phenotypes of cancer cells (30). In type 3 EMT, certain cancer cells with a transitioning mesenchymal phenotype undergo MET to form metastatic tumor nodules at distant sites $(1,2)$.

\section{EMT-inducing microenvironment}

The genetic and epigenetic alterations that cancer cells undergo render them sensitive to EMT-inducing signals. Highly motile mesenchyme-like cancer cells are typically observed at the invasive front, suggesting that dedifferentiating signals usually originate from the tumor microenvironment (30). As aforementioned, the reversibility of EMT suggests that epigenetic alterations, as a result of environmental signals, generate highly aggressive tumor phenotypes (31-34).

A hypoxic microenvironment is generally regarded as a potent inducer of EMT in various types of epithelial cancer $(30,35)$. In gliomas, inflammatory processes, or a hypoxic microenvironment within the tumor or neighboring normal tissues, may result in the recruitment of circulating or residential myeloid cells (including macrophages or microglia) into the tumor stroma (34). These cells release a number of growth factors, including TGF- $\beta$, epidermal growth factor, platelet-derived growth factor and fibroblast growth factor-2, which trigger alterations in the levels of transcription factors required for the initiation of EMT, and also in numerous proteases that increase invasiveness into the surrounding normal brain $(17,21,34,36)$. Thus, glioma cells that are affected by the bystander myeloid cells and such signaling molecules may undergo EMT in a hypoxic microenvironment.

\section{EMT-inducing signals in gliomas}

Twist. Twist is a protein with a basic helix-loop-helix structure and is transcriptionally active during cell differentiation and lineage determination $(37,38)$. During the establishment of 
cancer metastases by EMT, Twist acts independently of Snail to suppress E-cadherin and to upregulate $\mathrm{N}$-cadherin and fibronectin (38). Using a brain slice culture and an orthotopic model of xenotransplantation, it has been reported that Twist is upregulated in malignant gliomas, and promotes glioma cell invasion through the mesenchymal target gene Slug and the fibroblast activation protein, independent of the cadherin switch $(39,40)$. It has also been demonstrated that the inhibition of Twist expression results in a significant reduction in GBM stem cell sphere growth and formation. Nagaishi et al (41) observed that the expression of Twist is characteristic of mesenchymal areas of gliosarcomas, indicating that EMT is involved in the formation of biphasic tumor gliosarcoma.

Snail. Snail is a member of the SNAIL family of transcriptional activators and is a primary suppressor of E-cadherin expression $(1,2,42)$. Snail regulates a range of other EMT phenotypes, including the decreased expression of various epithelial markers (occludins, claudins and cytokeratin) and the increased expression of mesenchymal markers (vitronectin and fibronectin) (43). The transcriptional activity of Snail is predominantly regulated by its subcellular localization. Phosphorylation of Snail results in its exportation from the nucleus to the cytoplasm, leading to inactivation of the protein as a transcription factor (42). TGF- $\beta$ is secreted from mesenchymal cells following irradiation and induces the nuclear localization of Snail via Smad2/3 pathways (22).

Slug. Slug is another member of the SNAIL family of transcriptional activators and serves an important role in suppressing the epithelial phenotype in numerous cancer cells $(1,2,44)$. Slug is closely associated with the increased migration and invasion of malignant gliomas (45). A multi-cancer mesenchymal transition signature of mRNA expression levels from The Cancer Genome Atlas (TCGA) data has been highlighted by strong expression of Slug and cluster of differentiation (CD) $44(5,6)$.

$Z E B$. The zinc finger E-box-binding homeobox (ZEB) proteins, ZEB1 and smad1-interacting protein-1 (also known as ZEB2), are another family of noteworthy transcription factors that are responsible for the mediation of EMT in numerous types of cancer and glioma $(1,2,46)$. ZEB proteins bind to the promoter region of E-cadherin and suppress its expression, resulting in the loss of cell-cell contact and increased motility $(47,48)$. Wang et al (46) observed that patients with GBM containing high levels of ZEB2 demonstrated significantly earlier recurrence with malignant transformation compared to those with low levels of ZEB2. Connective tissue growth factor also renders glioma cells highly invasive through the activation of nuclear factor- $\kappa \mathrm{B}$, which subsequently initiates ZEB1 expression (49).

Wingless-related integration site $(W N T) / \beta$-catenin. In multiple types of cancer, $\beta$-catenin is sequestered in the cytoplasm by E-cadherin, with the translocation of $\beta$-catenin into the nucleus following the downregulation of E-cadherin being directly correlated with acquisition of the mesenchymal phenotype $(1,50,51)$. Although the majority of GBMs do not express E-cadherin, nuclear localization of $\beta$-catenin is primarily observed at the invasive front of the tumor (52). Furthermore,
GBMs that express high levels of WNT/ $\beta$-catenin are correlated with significantly shorter patient survival times (53). The WNT/ $\beta$-catenin pathway is an important stem cell maintenance pathway and is involved in therapy resistance (54). GBM cells, in which the WNT/ $\beta$-catenin pathway is activated, trigger the expression of a set of EMT activators, including Twist1, ZEB1, Snail and Slug (55). Furthermore, high expression levels of the WNT/ $\beta$-catenin receptor, Frizzled-4, promotes the expression of Snail and the acquirement of a mesenchymal phenotype in GBM (56).

NOTCH. NOTCH is a cell surface receptor that serves an important function in the development of numerous types of cells and tissues (1). NOTCH signaling is a primary inducer of EMT in a number of epithelial cancers, including cancer of the lung, breast and pancreas (57). Fan et al (58) reported that inhibition of this signaling pathway by $\gamma$-secretase inhibitors reduces CD133-positive stem-like cells in GBMs. In addition to $\mathrm{WNT} / \beta$-catenin, $\mathrm{NOTCH}$ is a major regulator of glioma stem cells within their microenvironments. NOTCH is also directly correlated with phosphoinositide-3 kinase/Akt pathway activation (59-61)

CD44. CD44 is a hyaluronic acid receptor that interacts with ligands such as collagens, osteopontin and matrix metalloproteases $(62,63)$. In addition to the standard isoform of CD44 (CD44s), alternative splicing results in 11 other isoforms of CD44 variants (CD44v2-v12) (64). CD44s is a primary inducer of EMT in breast and colorectal cancer. TCGA data indicates that GBMs with high levels of mRNA expression of EMT-inducing signature molecules, including Slug and CD44, are correlated with increased resistance to therapies and tumor invasion (65). However, functional data for CD44-mediated EMT in GBM have not been fully elucidated (66).

\section{MicroRNAs (miRs) that regulate EMT in gliomas}

miRs are small, 20-23-nucleotide non-coding RNAs that serve as epigenetic regulators of gene expression through the downregulation of target genes; this occurs through the binding of miRs to regions of partial complementarity in the target gene 3'-untranslated regions (67). Each miR has hundreds of target genes, and numerous genes are targeted by multiple miRs, creating a highly complex gene expression regulatory network (68). Control of gene expression by miRs is one of the most important modulating processes in cellular differentiation during normal embryogenesis $(69,70)$. A number of studies have demonstrated that miRs may function as negative regulators of gene expression in normal tissues and as tumor suppressors or oncogenes in various tumors $(67,70,71)$. In several types of cancer, epigenetic regulation (involving miRs) is a core mechanism of EMT modulation, and thus, reversible modulation of the genes that mediate EMT is possible (72). The majority of miRs are negatively correlated with tumorigenesis, tumor invasion and mesenchymal changes in gliomas. Notably, the expression of miR-21, $-34 a,-128 a,-124$ and -184 is correlated with the downregulation of mesenchymal markers and decreased invasiveness. By contrast, a relatively small number of miRs are oncogenic and may function as therapeutic targets. The 
inhibition of a Dicer enzyme for a specific oncogenic miR was recently indicated to block maturation of the miR and suppress tumor invasion (73). Furthermore, evidence is growing concerning the effect of miRs on the progression and maintenance of glioma stem cells $(67,71)$.

\section{Radiation-induced EMT}

Radiation therapy is a major modality of cancer therapy and also serves a key role in the multimodal treatment of GBM. However, irradiation that is sublethal to malignant glioma cells consequently promotes cell migration and invasion through the expression of TGF- $\beta$, epidermal growth factor, vascular endothelial growth factor (VEGF) and the hepatocyte growth factor pathway (74-76). Glioma cells that are resistant to irradiation have a gene expression signature that is enriched in the EMT pathway, leading to highly invasive recurrence patterns $(22,23,77,78)$. TCGA data indicates a shift from a proneural to mesenchymal phenotype at the time of tumor recurrence. Recently, Mahabir et al (22) observed that two different pathways are involved in the radiation-associated EMT induction in malignant gliomas; TGF- $\beta$, derived from the mesenchymal cells in the tumor environment, evokes the activation of Smad2/3, whilst reactive oxygen species activate extracellular signal-regulated kinase1/2, with each pathway leading to the nuclear localization of Snail. Such data suggests that EMT serves a crucial role in the acquisition of radiation resistance. Furthermore, emerging evidence suggests that such a role for EMT in the generation of refractory cancer cells is associated with an accumulation of stem cell markers. The NOTCH pathway and WNT/ $\beta$-catenin signaling are important for stem cell maintenance and are associated with the radiation resistance of GBM (78).

A further important aspect of the biological effects of radiation therapy on GBM is the induction of hypoxia or necrosis. Tissue hypoxia directly induces EMT and recruits myeloid cells into tumor tissues (15-20). Glioma cells, under a hypoxic microenvironment, and recruited myeloid cells each secrete TGF- $\beta$, leading to the induction of hypoxia-inducible factor- $1 \alpha$ (HIF-1 $\alpha$ ), which subsequently promotes the malignant progression of glioma cells $(21,79)$.

\section{Bevacizumab-induced EMT}

VEGF is one of the most important factors facilitating angiogenesis and resultant tumor growth in GBM. Inhibiting the VEGF-VEGF receptor (VEGFR) signal transduction pathway with anti-VEGF therapy (including the use of bevacizumab) and VEGFR inhibitors (including sunitinib) is a promising strategy in cancer therapy (80). Bevacizumab is effective in prolonging progression-free survival (PFS) in newly diagnosed GBM patients, but is not effective in prolonging overall survival $(81,82)$. During the early phases of bevacizumab therapy, tumor oxygenation improves through the process of vascular normalization (83). However, with prolonged treatment with bevacizumab, in a similar manner to radiation therapy, the tumor develops progressive hypoxia that directly or indirectly promotes the mesenchymal phenotype $(21,79,83)$. Furthermore, hypoxia induces the release of HIF-1 $\alpha$ from glioma cells and subsequently attracts myeloid cells, including macrophages and granulocytes, from bone marrow into the glioma tissues $(21,23)$. The recruited myeloid cells release TGF- $\beta$, which then directly induces EMT in the glioma cells. Myeloid cells also secrete multiple growth factors, including interleukin (IL)-6, IL-10 and matrix metalloproteinases (15-19). TGF- $\beta$, alongside VEGF, also recruits mesenchymal stem cells into the glioma tissues, which contributes to the further malignant progression of GBMs (83). By contrast, VEGFR inhibitors lack the efficacy in PFS prolongation, due to the induction of hypoxia in the early phase, without the vascular normalization phase, or due to dose-limiting adverse events. Similarly, anti-VEGF therapy is more effective than VEGFR inhibitors in decreasing myeloid cell infiltration, which may contribute to the efficacy of bevacizumab observed during early phases.

\section{Conclusion}

Glioma cells undergoing EMT acquire the potential to initiate metastasis and invasion. This process is highly affected by the tumor microenvironment, particularly a hypoxic environment or one involving the release of proinflammatory molecules from recruited myeloid or mesenchymal stem cells. The evidence that type I and II EMT occur during the normal physiological processes of embryogenesis and wound healing in a relatively short time suggests that epigenetic mechanisms are more crucial than genetic changes. This notion is also supported by the evidence that migrating tumor cells that have undergone EMT may also undergo MET to establish metastatic tumor nodules. Therefore, tumor microenvironments are emerging as a therapeutic target, particularly when in a hypoxic state, which controls epigenetic alterations in tumor cells. The microenvironmental modifier, bevacizumab, has recently been developed; however, future clinical trials to maximize the efficacy of anti-VEGF therapy are required, with the aim that such treatment will normalize oxygen concentration and suppress the excessive recruitment of myeloid and mesenchymal stem cells.

\section{References}

1. Kalluri R and Weinberg RA: The basics of epithelial-mesenchymal transition. J Clin Invest 119: 1420-1428, 2009.

2. Zeisberg M and Neilson EG: Biomarkers for epithelial-mesenchymal transitions. J Clin Invest 119: 1429-1437, 2009.

3. KahlertUD,NikkhahGandMaciaczykJ:Epithelial-to-mesenchymal (-like) transition as a relevant molecular event in malignant gliomas. Cancer Lett 331: 131-138, 2013.

4. Mani SA, Guo W, Liao MJ, Eaton EN, Ayyanan A, Zhou AY, Brooks M, Reinhard F, Zhang CC, Shipitsin M, et al: The epithelial-mesenchymal transition generates cells with properties of stem cells. Cell 133: 704-715, 2008.

5. Phillips HS, Kharbanda S, Chen R, Forrest WF, Soriano RH, Wu TD, Misra A, Nigro JM, Colman H, Soroceanu L, et al: Molecular subclasses of high-grade glioma predict prognosis, delineate a pattern of disease progression, and resemble stages in neurogenesis. Cancer Cell 9: 157-173, 2006.

6. Verhaak RGW, Hoadley KA, Purdom E, Wang V, Qi Y, Wilkerson MD, Miller CR, Ding L, Golub T, Mesirov JP, et al; Cancer Genome Atlas Research Network: Integrated genomic analysis identifies clinically relevant subtypes of glioblastoma characterized by abnormalities in PDGFRA, IDH1, EGFR, and NF1. Cancer Cell 17: 98-110, 2010.

7. Zarkoob H, Taube JH, Singh SK, Mani SA and Kohandel M: Investigating the link between molecular subtypes of glioblastoma, epithelial-mesenchymal transition, and CD133 cell surface protein. PLoS One 8: e64169, 2013. 
8. Bao S, Wu Q, McLendon RE, Hao Y, Shi Q, Hjelmeland AB, Dewhirst MW, Bigner DD and Rich JN: Glioma stem cells promote radioresistance by preferential activation of the DNA damage response. Nature 444: 756-760, 2006.

9. Bhat KPL, Balasubramaniyan V, Vaillant B, Ezhilarasan R, Hummelink K, Hollingsworth F, Wani K, Heathcock L, James JD, Goodman LD, et al: Mesenchymal differentiation mediated by $\mathrm{NF}-\kappa \mathrm{B}$ promotes radiation resistance in glioblastoma. Cancer Cell 24: 331-346, 2013.

10. Zhang X, Zhang W, Mao XG, Zhen HN, Cao WD and Hu SJ: Targeting role of glioma stem cells for glioblastoma multiforme. Curr Med Chem 20: 1974-1984, 2013.

11. Murat A,MigliavaccaE,GorliaT,Lambiv WL,Shay T,HamouMF, de Tribolet N, Regli L, Wick W, Kouwenhoven MC, et al: Stem cell-related 'self-renewal' signature and high epidermal growth factor receptor expression associated with resistance to concomitant chemoradiotherapy in glioblastoma. J Clin Oncol 26: 3015-3024, 2008.

12. Kleihues P and Cavenee WK (eds): Pathology and genetics of tumors of the nervous system. In: World Health Organization Classification of Tumours. Pathology and Genetics of Head and Neck Tumours. IARC Press, Lyon, France, pp9-15, 2000.

13. Kahlert UD, Maciaczyk D, Doostkam S, Orr BA, Simons B, Bogiel T, Reithmeier T, Prinz M, Schubert J, Niedermann G, et al: Activation of canonical WNT/ $\beta$-catenin signaling enhances in vitro motility of glioblastoma cells by activation of ZEB1 and other activators of epithelial-to-mesenchymal transition. Cancer Lett 325 42-53, 2012.

14. Brabletz T: To differentiate or not - routes towards metastasis Nat Rev Cancer 12: 425-436, 2012.

15. Baysan M, Woolard K, Bozdag S, Riddick G, Kotliarova S, Cam MC, Belova GI, Ahn S, Zhang W, Song H, et al: Micro-environment causes reversible changes in DNA methylation and mRNA expression profiles in patient-derived glioma stem cells. PLoS One 9: e94045, 2014.

16. Heddleston JM, Li Z, McLendon RE, Hjelmeland AB and Rich JN: The hypoxic microenvironment maintains glioblastoma stem cells and promotes reprogramming towards a cancer stem cell phenotype. Cell Cycle 8: 3274-3284, 2009.

17. Cooper LA, Gutman DA, Chisolm C, Appin C, Kong J, Rong Y, Kurc T, Van Meir EG, Saltz JH, Moreno CS and Brat DJ: The tumor microenvironment strongly impacts master transcriptional regulators and gene expression class of glioblastoma. Am J Pathol 180: 2108-2119, 2012

18. BarEE, Lin A, Mahairaki V, Matsui W and Eberhart CG: Hypoxia increases the expression of stem-cell markers and promotes clonogenicity in glioblastoma neurospheres. Am J Pathol 177: 1491-1502, 2010

19. Evans SM, Judy KD, Dunphy I, Jenkins WT, Hwang WT, Nelson PT, Lustig RA, Jenkins K, Magarelli DP, Hahn SM, et al: Hypoxia is important in the biology and aggression of human glial brain tumors. Clin Cancer Res 10: 8177-8184, 2004.

20. Schonberg DL, Lubelski D, Miller TE and Rich JN: Brain tumor stem cells: Molecular characteristics and their impact on therapy. Mol Aspects Med 39: 82-101, 2014.

21. Piao Y, Liang J, Holmes L, Zurita AJ, Henry V, Heymach JV and de Groot JF: Glioblastoma resistance to anti-VEGF therapy is associated with myeloid cell infiltration, stem cell accumulation, and a mesenchymal phenotype. Neuro Oncol 14: 1379-1392, 2012.

22. Mahabir R, Tanino M, Elmansuri A, Wang L, Kimura T, Itoh T, Ohba Y, Nishihara H, Shirato H, Tsuda M and Tanaka S: Sustained elevation of Snail promotes glial-mesenchymal transition after irradiation in malignant glioma. Neuro Oncol 16: 671-685, 2014

23. Kim YH, Yoo KC, Cui YH, Uddin N, Lim EJ, Kim MJ, Nam SY, Kim IG, Suh Y and Lee SJ: Radiation promotes malignant progression of glioma cells through HIF-1alpha stabilization. Cancer Lett 354: 132-141, 2014.

24. Knecht AK and Bronner-Fraser M: Induction of the neural crest: A multigene process. Nat Rev Genet 3: 453-461, 2002

25. Zeisberg M, Hanai J, Sugimoto H, Uddin N, Lim EJ, Kim MJ, Nam SY, Kim IG, Suh Y and Lee SJ: BMP-7 counteracts TGF-beta-1-induced epithelial-to mesenchymal transition and reverses chronic renal injury. Nat Med 9: 964-968, 2003.

26. Yu Y, Xiao CH, Tan LD, Wang QS, Li XQ and Feng YM. Cancer-associated fibroblasts induce epithelial-mesenchymal transition of breast cancer cells through paracrine TGF- $\beta$ signaling. Br J Cancer 110: 724-732, 2014.

27. Bierie B and Moses HL: Tumour microenvironment: TGFbeta: The molecular Jekyll and Hyde of cancer. Nat Rev Cancer 6 : 506-520, 2006
28. Song J: EMT or apoptosis: A decision for TGF-beta. Cell Res 17: 289-290, 2007

29. Bhowmick NA, Zent R, Ghiassi M, McDonnell M and Moses HL: Integrin beta 1 signaling is necessary for transforming growth factor-beta activation of p38MAPK and epithelial plasticity. J Biol Chem 276: 46707-46713, 2001.

30. Charles NA, Holland EC, Gilbertson R, Glass R and Kettenmann H: The brain tumor microenvironment. Glia 59: 1169-1180, 2011.

31. Dumont N, Wilson MB, Crawford YG, Reynolds PA, Sigaroudinia M and Tlsty TD: Sustained induction of epithelial to mesenchymal transition activates DNA methylation of genes silenced in basal-like breast cancers. Proc Natl Acad Sci USA 105 14867-14872, 2008.

32. Hirohashi S: Inactivation of the E-cadherin-mediated cell adhesion system in human cancers. Am J Pathol 153: 333-339, 1998.

33. Birchmeier W and Behrens J: Cadherin expression in carcinomas: Role in the formation of cell junctions and the prevention of invasiveness. Biochim Biophys Acta 1198: 11-26, 1994.

34. Ye XZ,Xu SL, Xin YH, Yu SC, Ping YF, Chen L, Xiao HL, Wang B, Yi L, Wang QL, et al: Tumor-associated microglia/macrophages enhance the invasion of glioma stem-like cells via TGF- $\beta 1$ signaling pathway. J Immunol 189: 444-453, 2012.

35. Jensen RL: Brain tumor hypoxia: Tumorigenesis, angiogenesis, imaging, pseudoprogression, and as a therapeutic target. J Neurooncol 92: 317-335, 2009.

36. Iwadate Y, Sakaida T, Hiwasa T, Nagai Y, Ishikura H, Takiguchi M and Yamaura A: Molecular classification and survival prediction in human gliomas based on proteome analysis. Cancer Res 64: 2496-2501, 2004

37. Castanon L and Baylies MK: A Twist in fate: Evolutionary comparison of Twist structure and function. Gene 287: 11-22, 2002.

38. Yang MH, Wu MZ, Chiou SH, Chen PM, Chang SY, Liu CJ, Teng SC and Wu KJ: Direct regulation of TWIST by HIF-1alpha promotes metastasis. Nat Cell Biol 10: 295-305, 2008.

39. Elias MC, Tozer KR, Silber JR, Mikheeva S, Deng M, Morrison RS, Manning TC, Silbergeld DL, Glackin CA, Reh TA and Rostomily RC: Twist is expressed in human gliomas and promotes invasion. Neoplasia 7: 824-837, 2005.

40. Mikheeva SA, Mikheev AM, Petit A, Beyer R, Oxford RG, Khorasani L, Maxwell JP, Glackin CA, Wakimoto $\mathrm{H}$, González-Herrero I, et al: TWIST1 promotes invasion through mesenchymal change in human glioblastoma. Mol Cancer 9: 194, 2010.

41. Nagaishi M, Paulus W, Brokinkel B, Vital A, Tanaka Y, Nakazato Y, Giangaspero F and Ohgaki H: Transcriptional factors for epithelial-mesenchymal transition are associated with mesenchymal differentiation in gliosarcoma. Brain Pathol 22: 670-676, 2012

42. Boutet A, De Frutos CA, Maxwell PH, Mayol MJ, Romero J and Nieto MA: Snail activation disrupts tissue homeostasis and induces fibrosis in the adult kidney. EMBO J 25: 5603-5613, 2006.

43. Cheng WY, Kandel JJ, Yamashiro DJ, Canoll P and Anastassiou D: A multi-cancer mesenchymal transition gene expression signature is associated with prolonged time to recurrence in glioblastoma. PLoS One 7: e34705, 2012

44. Yang HW, Menon LG, Black PM, Carroll RS and Johnson MD: SNAI2/Slug promotes growth and invasion in human gliomas. BMC Cancer 10: 301, 2010.

45. Xie YK, Huo SF, Zhang G, Zhang F, Lian ZP, Tang XL and Jin C: CDA-2 induces cell differentiation through suppressing Twist/SLUG signaling via miR-124 in glioma. J Neurooncol 110: 179-186, 2012.

46. Wang Q, Li X, Zhu Y and Yang P: MicroRNA-16 suppresses epithelial-mesenchymal transition-related gene expression in human glioma. Mol Med Rep 10: 3310-3314, 2014.

47. Sánchez-Tilló E, Liu Y, de Barrios O, Siles L, Fanlo L, Cuatrecasas M, Darling DS, Dean DC, Castells A and Postigo A EMT-activating transcription factors in cancer: Beyond EMT and tumor invasiveness. Cell Mol Life Sci 69: 3429-3456, 2012.

48. Qi S, Song Y, Peng Y, Wang H, Long H, Yu X, Li Z, Fang L, $\mathrm{Wu} A$, Luo W, et al: ZEB2 mediates multiple pathways regulating cell proliferation, migration, invasion, and apoptosis in glioma. PLoS One 7: e38842, 2012.

49. Edwards LA, Woolard K, Son MJ, Li A, Lee J, Ene C, Mantey SA, Maric D, Song H, Belova G, et al: Effect of brain- and tumor-derived connective tissue growth factor on glioma invasion. J Natl Cancer Inst 103: 1162-1178, 2011. 
50. Thiery JP: Epithelial-mesenchymal transitions in tumour progression. Nat Rev Cancer 2: 442-454, 2002.

51. Kim K, Lu Z and Hay ED: Direct evidence for a role of beta-catenin/LEF-1 signaling pathway in induction of EMT. Cell Biol Int 26: 463-476, 2002.

52. Paul I, Bhattacharya S, Chatterjee A and Ghosh MK: Current understanding on EGFR and Wnt/ $\beta$-catenin signaling in glioma and their possible crosstalk. Genes Cancer 4: 427-446, 2013.

53. Sandberg CJ, Altschuler G, Jeong J, Strømme KK, Stangeland B, Murrell W, Grasmo-Wendler UH, Myklebost O, Helseth E, Vik-Mo EO, et al: Comparison of glioma stem cells to neural stem cells from the adult human brain identifies dysregulated Wnt- signaling and a fingerprint associated with clinical outcome. Exp Cell Res 319: 2230-2243, 2013.

54. Clevers H, Loh KM and Nusse R: Stem cell signaling. An integral program for tissue renewal and regeneration: Wnt signaling and stem cell control. Science 346: 1248012, 2014.

55. Gong $\mathrm{A}$ and Huang S: FoxM1 and Wnt/ $\beta$-catenin signaling in glioma stem cells. Cancer Res 72: 5658-5662, 2012.

56. Jin X, Jeon HY, Joo KM, Kim JK, Jin J, Kim SH, Kang BG, Beck S, Lee SJ, Kim JK, et al: Frizzled 4 regulates stemness and invasiveness of migrating glioma cells established by serial intracranial transplantation. Cancer Res 71: 3066-3075, 2011

57. Brabletz S, Bajdak K, Meidhof S, Burk U, Niedermann G, Firat E, Wellner U, Dimmler A, Faller G, Schubert J and Brabletz T: The ZEB1/miR-200 feedback loop controls NOTCH signalling in cancer cells. EMBO J 30: 770-782, 2011.

58. Fan X, Khaki L, Zhu TS, Soules ME, Talsma CE, Gul N, Koh C, Zhang J, Li YM, Maciaczyk J, et al: NOTCH pathway blockade depletes CD133-positive glioblastoma cells and inhibits growth of tumor neurospheres and xenografts. Stem Cells 28: 5-16, 2010.

59. Hu YY, Fu LA, Li SZ, Chen Y, Li JC, Han J, Liang L, Li L, Ji CC, Zheng MH and Han H: Hif- $1 \alpha$ and Hif- $2 \alpha$ differentially regulate NOTCH signaling through competitive interaction with the intracellular domain of NOTCH receptors in glioma stem cells. Cancer Lett 349: 67-76, 2014.

60. Kristoffersen K, Villingshøj M, Poulsen HS and Stockhausen MT: Level of NOTCH activation determines the effect on growth and stem cell-like features in glioblastoma multiforme neurosphere cultures. Cancer Biol Ther 14: 625-637, 2013.

61. Stockhausen MT, Kristoffersen K and Poulsen HS: NOTCH signaling and brain tumors. Adv Exp Med Biol 727: 289-304, 2012

62. Anido J, Sáez-Borderías A, Gonzàlez-Juncà A, Rodón L, Folch G, Carmona MA, Prieto-Sánchez RM, Barba I, Martínez-Sáez E, Prudkin L, et al: TGF- $\beta$ receptor inhibitor target CD44(high)/Id1(high) glioma-initiating cell population in human glioblastoma. Cancer Cell 18: 655-668, 2010.

63. Kaaijk P, Troost D, Morsink F, Keehnen RM, Leenstra S, Bosch DA and Pals ST: Expression of CD44 splice variants in human primary brain tumors. J Neurooncol 26: 185-190, 1995.

64. Merzak A, Koocheckpour S and Pilkington GJ: CD44 mediates human glioma cell adhesion and invasion in vitro. Cancer Res 54 3988-3992, 1994.

65. Xu Y, Stamenkovic I and Yu Q: CD44 attenuates activation of the hippo signaling pathway and is a prime therapeutic target for glioblastoma. Cancer Res 70: 2455-2464, 2010.

66. Wei KC, Huang CY, Chen PY, Feng LY, Wu TWE, Chen SM, Tsai HC, Lu YJ, Tsang NM, Tseng CK, et al: Evaluation of the prognostic value of CD44 in glioblastoma multiforme. Anticancer Res 30: 253-259, 2010.

67. Katsushima K and Kondo Y: Non-coding RNAs as epigenetic regulator of glioma stem-like cell differentiation. Front Genet 5: 14, 2014.
68. Montagner S, Dehó L and Monticelli S: MicroRNAs in hematopoietic development. BMC Immunol 15: 14, 2014.

69. Piubelli C, Meraviglia V, Pompilio G, D'Alessandra Y, Colombo GI and Rossini A: MicroRNAs and cardiac cell fate. Cells 3: 802-823, 2014.

70. Godlewski J, Newton HB, Chiocca EA and Lawler SE: MicroRNAs and glioblastoma; the stem cell connection. Cell Death Differ 17: 221-228, 2010.

71. Møller HG, Rasmussen AP, Andersen HH, Johnsen KB, Henriksen M and Duroux M: A systematic review of microRNA in glioblastoma multiforme: Micro-modulators in the mesenchymal mode of migration and invasion. Mol Neurobiol 47: 131-144, 2013.

72. Bullock MD, Sayan AE, Packham GKand Mirnezami AH: MicroRNAs: Critical regulators of epithelial to mesenchymal (EMT) and mesenchymal to epithelial transition (MET) in cancer progression. Biol Cell 104: 3-12, 2012.

73. Shi Z, Zhang J, Qian X, Han L, Zhang K, Chen L, Liu J, Ren Y, Yang M, Zhang A, et al: AC1MMYR2, an inhibitor of dicer-mediated biogenesis of Oncomir miR-21, reverses epithelial-mesenchymal transition and suppresses tumor growth and progression. Cancer Res 73: 5519-5531, 2013.

74. Zhang M, Kleber S, Röhrich M, Timke C, Han N, Tuettenberg J, Martin-Villalba A, Debus J, Peschke P, Wirkner U, et al: Blockade of TGF- $\beta$ signaling by the TGF $\beta$ R-I kinase inhibitor LY2109761 enhances radiation response and prolongs survival in glioblastoma. Cancer Res 71: 7155-7167, 2011.

75. Timke C, Zieher H, Roth A, Hauser K, Lipson KE, Weber KJ, Debus J, Abdollahi A and Huber PE: Combination of vascular endothelial growth factor receptor/platelet-derived growth factor receptor inhibition markedly improves radiation tumor therapy. Clin Cancer Res 14: 2210-2219, 2008.

76. Zhou YC, Liu JY, Li J, Zhang J, Xu YQ, Zhang HW, Qiu LB, Ding GR, Su XM, Mei-Shi and Guo GZ: Ionizing radiation promotes migration and invasion of cancer cells through transforming growth factor-beta-mediated epithelial-mesenchymal transition. Int J Radiat Oncol Biol Phys 81: 1530-1537, 2011.

77. Theys J, Jutten B, Habets R, Paesmans K, Groot AJ, Lambin P, Wouters BG, Lammering $\mathrm{G}$ and Vooijs M: E-Cadherin loss associated with EMT promotes radioresistance in human tumor cells. Radiother Oncol 99: 392-397, 2011.

78. Meng J, Li P, Zhang Q, Yang Z and Fu S: A radiosensitivity gene signature in predicting glioma prognostic via EMT pathway. Oncotarget 5: 4683-4693, 2014

79. Piao Y, Liang J, Holmes L, Henry V, Sulman E and de Groot JF: Acquired resistance to anti-VEGF therapy in glioblastoma is associated with a mesenchymal transition. Clin Cancer Res 19: 4392-4403, 2013

80. Jain RK: Normalization of tumor vasculature: An emerging concept in antiangiogenic therapy. Science 307: 58-62, 2005.

81. Gilbert MR, Dignam JJ, Armstrong TS, Wefel JS, Blumenthal DT, Vogelbaum MA, Colman H, Chakravarti A, Pugh S, Won M, et al: A randomized trial of bevacizumab for newly diagnosed glioblastoma. N Engl J Med 370: 699-708, 2014.

82. Chinot OL, Wick W, Mason W, Henriksson R, Saran F, Nishikawa R, Carpentier AF, Hoang-Xuan K, Kavan P, Cernea D, et al: Bevacizumab plus radiotherapy-temozolomide for newly diagnosed glioblastoma. N Engl J Med 370: 709-722, 2014.

83. Behnan J, Isakson P, Joel M, Cilio C, Langmoen IA, Vik-Mo EO and Badn W: Recruited brain tumor-derived mesenchymal stem cells contribute to brain tumor progression. Stem Cells 32: 1110-1123, 2014. 